\title{
PROPOSAL OF A MODEL FOR MEASURING VALUE IN THE DESIGN PROCESS
}

\author{
Zulay Giménez ${ }^{1}$, Claudio Mourgues ${ }^{2}$, Luis F. Alarcón ${ }^{3}$ and Harrison Mesa ${ }^{4}$
}

\begin{abstract}
Among the current challenges associated with design in the Architecture, Engineering and Construction (AEC) industry is the need for an adequate understanding of the value required by involved customers to avoid decreases in productivity and value losses in the process and product. This paper describes the development of a value analysis model with the conceptual basis of Design Science Research (DSR) and based on Kano'smodel, which seeks to accomplish the following: (1) identify the desired value of the different clients in the process; (2) understand the value generation process; and (3) conveniently recognize and manage value losses. This paper is based on an existing case study of the Kano's model found in the literature to evaluate the proposed model. The main contribution is the creation of 3 value indexes-Desired, Potential and Generated - which inform designers of the presence of different degrees of value losses and support the improvement of the capture of requirements and the knowledge of customer satisfaction conditions. The current limitation of the model is the noncorporation of the utilized resources as part of the value equation.
\end{abstract}

\section{KEYWORDS}

Value, value losses, kano model, design science, value index, value analysis

\section{INTRODUCTION}

The Architecture, Engineering and Construction (AEC) industry recognizes the design process as a key to the success (or failure) of projects(Knotten et al. 2016). Although design costs are often less than one percent of the life cycle cost of a project(Andi \& Minato 2003), they have a major influence on the total cost and performance of the project(Love et al. 2013).

1 PhD. cadidate, School of Engineering, Pontificia Universidad Católica de Chile, Santiago, Chile. E-Mail: zmgimenez@ing.puc.cl

2 Associate Professor of Civil Engineering, School of Engineering, Pontificia Universidad Católica de Chile, Santiago, Chile. E-Mail: cmourgue @ ing.puc.cl

3 Professor of Civil Engineering, School of Engineering, Pontificia Universidad Católica de Chile, Santiago, Chile. E-Mail: lalarcon@ing.puc.cl

4 Assistant Professor of Civil Construction, School of Civil Construction, Pontificia Universidad Católica de Chile, Santiago, Chile. 
The decrease in productivity of the AEC industry, rework and construction failures are partly attributed to design flaws(Andi \& Minato 2003). The most important reasons for project failure include incomplete requirements, unrealistic expectations, multiple changes in requirements and specifications, and lack of user involvement(The Standish Group 2014). In the construction industry, user interaction during the design process has traditionally be considered to be as a nuisance(Arge 2008). The conditions of customer satisfaction are poorly known; an extensive knowledge of "how to do things" (technology and business model) exists with an inadequate understanding of patterns of lifestyles, work and learning(Kumar \& Whitney 2007). If customer values are not fully understood in a construction project, the result will probably be low compliance with customer expectations or multiple modifications during the project(Spiten et al. 2016), which represents value losses from the value perspective proposed by Koskela (2000) because part of the value is not provided even though it is potentially possible.

Challenges associated with design include the appropriate formulation of requirements and interactive and multidimensional management to represent the interests of stakeholders(Male et al. 2007). Most design deficiencies are identified at a later stage (during construction), with the possibility that some deficiencies will remain undetected(Love et al. 2013).

This paper describes the development of a value analysis model in real estate design. To address these challenges, it is necessary to understand how the value is generated during the design process. Understanding value as the relationship between the fulfilment of needs and the utilized resources (Association Francaise de Normalisation 2000), this model seeks to accomplish the following: (1) identify the desired value of the different clients in the process via the classification of requirements; (2) understand the process of generating value in the design; and (3) conveniently recognize and manage value losses.

\section{BACKGROUND}

\section{CONCEPT OF VALUE}

Value is defined as the relationship between the fulfillment of needs and the resources that are implemented for this fulfillment(Association Francaise de Normalisation 2000). Historically, the value of the project was communicated in monetary terms as a relationship between costs and benefits(Rachwan et al. 2016). Currently, we can visualize different concepts of value with a similar approach: value is expressed as a relation between function and total life cycle cost of this function(Orihuela et al. 2015), or as the relation between "what you get/what you give", "balance of benefits and sacrifices involved in a value judgment"(Saxon 2005) and the relation between the value of the product of a process and the value (or cost) of the inputs for this process(Koskela 2000). These definitions are related, as shown in Figure 1. 


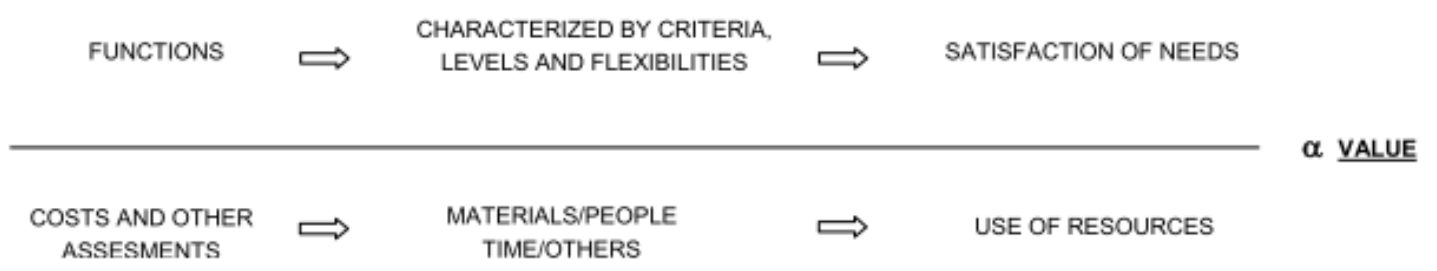

Figure 1. Relationships between the elements that build value(Association Francaise de Normalisation, 2000).

Other research defines value in terms of use, exchange/replacement, performance, and estimated cost(Rachwan et al. 2016). Value is not absolute; value is relative and is perceived in different ways by different parties in different situations(Cuperus \& Napolitano 2005), and it is dependent on the theoretical context, subjective perceptions and evaluative judgements(Drevland \& Lohne 2015), it means that value for one person is different from value for other people(Koskela 2000).

In the context of Lean Production, value is defined from the perspective of customers(Womack \& Jones 1996); it is an assessment that is made in relation to a series of concerns that someone wants to address(Macomber et al. 2007) to obtain a desired product(Bølviken et al. 2014) and to determine what customers need to achieve their goals(Rybkowski et al. 2012).

\section{DESIGN AS PRODUCTION}

Design is a systematic process for identifying, exploring and exploiting value opportunities(Lee \& Paredis 2014). Although there are differences between material production and the intellectual activity of design (greater iteration and uncertainty in design and greater repetition of activities in production), design is visualized as a productive process from three points of view: transformation, flow and value generation(Koskela 2000).

While the transformation and flow perspective internally focuses on the production process in a manner in which it is efficiently performed and eliminates waste or activities that do not add value, the value perspective focuses on the external result of the process, where the value of the client is created by compliance with its requirements and elimination of value losses (value achieved in relation to the best possible value)(Koskela 2000).

\section{VALUE MANAGEMENT}

Value management, which is also known as value analysis, value methodology or value engineering(Rachwan et al. 2016), is a management style that has evolved from previous methods based on the concept of value and a functional approach. In value management, an objective setting considers the psychological needs and desires of the participants, and subsequent analysis considers the deviation between the desired value and that offered by existing macro and micro environments; once this value gap has been identified, participants approve the criteria for seeking the desirable value(Leung \& Liu 1998). 


\section{KANO MODEL}

The Kano model (1984) is an effective tool for the identification and interpretation of the "voice of the client" because it enables a singular classification of the customer's requirements (attributes) toward the product and its subsequent characterization in the design(Arroyave et al. 2007).

Kano et al (1984) categorize attributes as follows (Matzler et al.): (1) Must-be (M): these are the basic elements of a product; if these attributes are not satisfied, extreme customer dissatisfaction will ensue. (2) One-dimensional $(\mathrm{O})$ : customer satisfaction is proportional to the level of compliance with these attributes. (3) Attractive (A): these are attributes that are not explicitly expressed or requested by the customer, but they have a substantial influence on the satisfaction of a customer with a particular product. (4) Indifferent (I): the presence or absence of these attributes does not contribute to either increasing or decreasing customer satisfaction. (5) Reverses (R): these product characteristics are not desired by the customer; rather, the opposite characteristics are expected (Matzler et al. 1996). Figure 2 graphically depicts the Kano model.

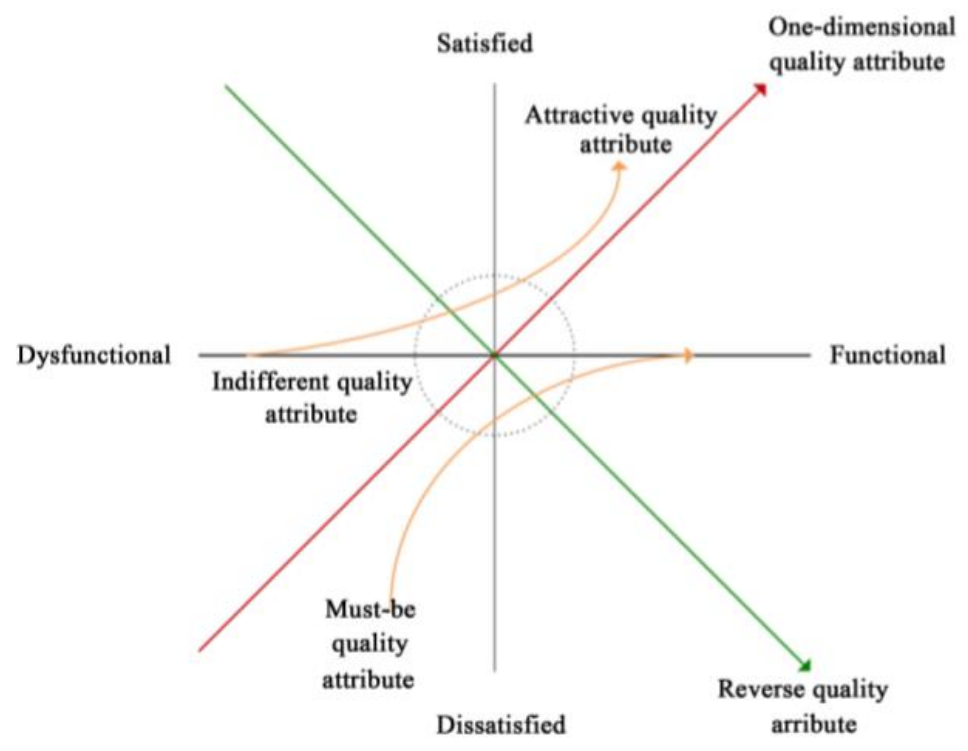

Figure 2. Kano Model(Huang 2017)

\section{KANO QUESTIONNAIRE}

To implement the Kano model, a two-dimensional questionnaire is prepared, i.e., two questions for each product/service attribute(Huang 2017). The goal of the first question is to learn how customers feel if the proposed feature is present (functional question), while the goal of the second question is to learn how customers feel if the intended feature is not present (dysfunctional question). Each of the questions has the following answer options: 1. Like, 2. Must-be, 3. Neutral, 4. Live with, and 5. Dislike.

After administering the survey, the results are evaluated with the matrix shown in Table 1 to determine how most clients expressed their needs. Two possible contradictory responses exist; they are expressed as questionable (Q). 
Table 1. Kano's evaluation matrix(Huang 2017)

\begin{tabular}{cccccc}
\hline \multirow{2}{*}{ Functional } & \multicolumn{5}{c}{ Dysfunctional } \\
\cline { 2 - 6 } & Like & Must-be & Neutral & Live-with & Dislike \\
\hline Like & Q & A & A & A & O \\
Must-be & R & I & I & I & M \\
Neutral & R & I & I & I & M \\
Live-with & R & I & I & I & M \\
Dislike & R & R & R & R & Q \\
\hline
\end{tabular}

$\mathrm{A}=$ Attractive, $\mathrm{I}=$ Indifferent, $\mathrm{M}=$ Must-be, $\mathrm{O}=$ One-dimensional, $\mathrm{Q}=$ Questionable, and $\mathrm{R}=$ Reverse.

\section{CoEfFicient of SATISFACTion}

If the percentage of one of the categories is substantially higher than the other categories, the result is considered to be conclusive. When two Kano categories have the same assessment or very similar assessments of the first score, other considerations should be taken(Berger et al. 1993). Berger et al. (1993) proposed the coefficient of satisfaction to relate other categories to determine both the satisfaction and the dissatisfaction levels(Matzler et al. 1996), which indicates the average impact of the requirements on the satisfaction of all customers(Tontini 2002). This coefficient considers the best value or degree of satisfaction (SI) and the worst value or degree of dissatisfaction (DI) with the following formulas:

$$
\mathrm{SI}=(\mathrm{A}+\mathrm{O}) /(\mathrm{A}+\mathrm{O}+\mathrm{M}+\mathrm{I}) ; \quad \mathrm{DI}=(\mathrm{M}+\mathrm{O}) /(\mathrm{A}+\mathrm{O}+\mathrm{M}+\mathrm{I})
$$

A: Attractive, O: One-dimensional, M: Must-be, I: Indifferent

After calculating the SI and DI results, the coordinate system shown in Figure 3 is employed, in which the X coordinate represents SI and the Y coordinate represents DI. Each attribute is assigned to one of the quadrants of the coordinate axis, which corresponds to the categories of Kano(Huang 2017). In this way, a more distinct classification is obtained, especially in the previously mentioned cases.

\section{DI}

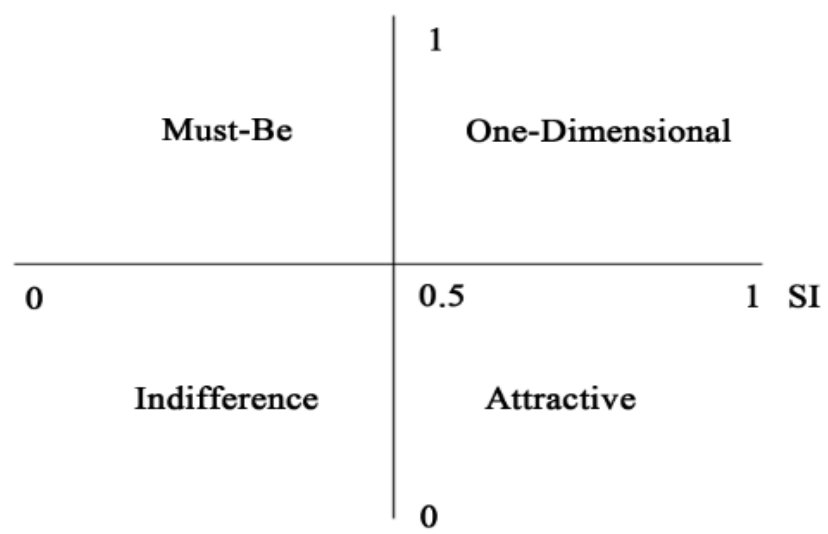

Figure 3. Coordinate system of the Kano type.(Huang, 2017) 


\section{RESEARCH PURPOSE}

The development of a value analysis model is proposed for application in the design process to understand the process of value generation and value losses via the classification of requirements and the formulation of value indicators.

\section{RESEARCH METHODOLOGY}

The analysis model has been developed on the conceptual basis of Design Science Research (DSR). DSR is based on three inherent research cycles(Hevner 2007). The Relevance Cycle connects the contextual environment of the research project with the scientific design activities. The Rigorous Cycle connects the scientific activities of design with the knowledge base of the scientific bases, experience and knowledge that comprise the research project. The central design cycle is inserted between the main construction activities and the evaluation of research design products and processes. The model has not been formally applied in context. Therefore, a case that was investigated by Huang(2017) will be used to settle this limitation.

\section{DEVELOPMENT OF THE MODEL}

The value analysis model shown in Figure 4 proposes to analyze the object to be evaluated (design inputs, design process and design product) and relate it to the phase of the project (pre-design, design, pre-construction and construction) and the customer involved (user, owner, specialties, reviewers and builders). Each of these clients in the different stages of the design process has a desired value with respect to the product, sub-product or design process. This information is projected to determine the desired value and the potentially possible value within the considered phase and obtain the Desired Value and Potential Value Indexes. In the design phase, the value is generated; therefore, the Generated Value Index can be obtained. This last index can be compared with previous indexes to determine if a sufficient value has been generated or if losses of value are identified. How the indexes are determined will be subsequently explained.

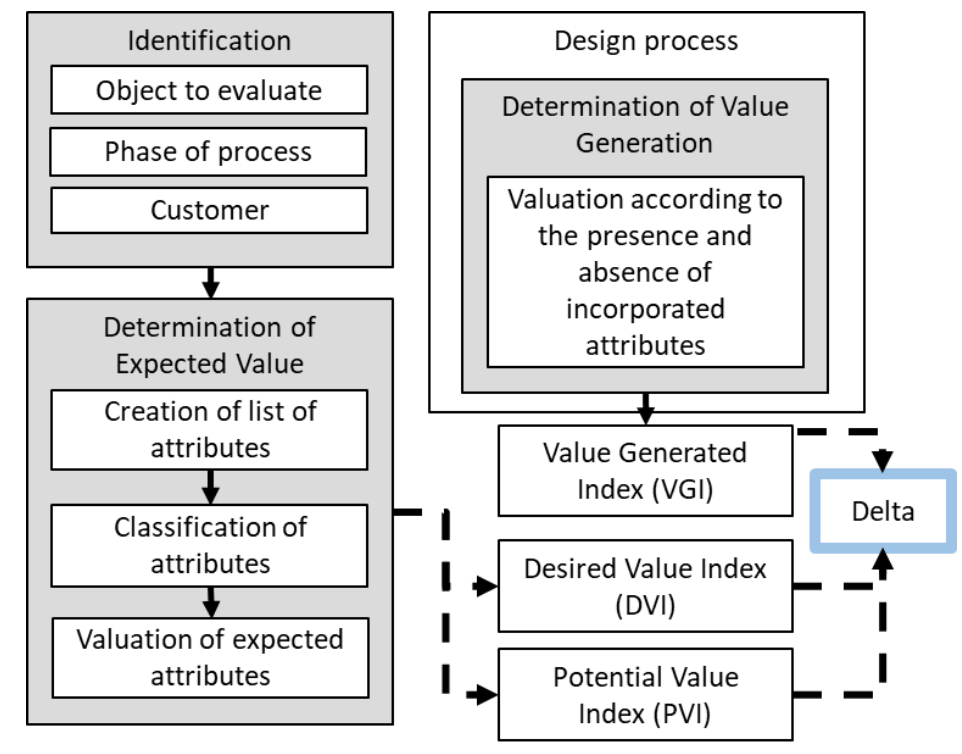


Figure 4. Proposed Value Analysis Model

\section{Determination of Desired Value and Potential Value}

Step 1: Elaboration of the list of attributes. In this list of attributes, must be customer needs and requirements must be considered. Delphi's method is proposed to create this list due to the importance of the systematic use of a judgment issued by a group of experts in the area. The list should also be supported by a review of literature, review of regulations and previous experience.

Step 2: Attribute classification. Attributes should be classified because some attributes do not have the same value for the client. For this reason, the use of the Kano model has been considered. Attributes that must be fulfilled by regulations, are considered like "must-be", are not included in the Kano questionnaire, and the remainder of the attributes are surveyed. If any doubt exists regarding the classification, the satisfaction coefficient proposed by Berger et al.(1993) is applied. In making this coefficient originally, questionable and reverse answers were consciously ignored(Berger et al. 1993). The reason is not questioned and is beyond the scope of this paper. However, in this research, reverse attributes are included within the coefficient because their presence may negatively influence it. For this reason, the reverse attribute will be included in the satisfaction coefficient as follows:

$\mathrm{SI}=(\mathrm{A}+\mathrm{O}-\mathrm{R}) /(\mathrm{A}+\mathrm{O}+\mathrm{M}+\mathrm{I}+\mathrm{R}) ; \quad \mathrm{DI}=(\mathrm{M}+\mathrm{O}+\mathrm{R}) /(\mathrm{A}+\mathrm{O}+\mathrm{M}+\mathrm{I}+\mathrm{R})$.

A: Attractive, O: One-dimensional, R: Reverses, M: Must-be, I: Indifferent

As an example, Table 2 shows a hypothetical case of two attributes after being surveyed. $R 1$ shows equal results towards the Reverse and Indifferent classification $(R=20, I=20)$; thus, we should use the coefficient of satisfaction (CS) to decide. Since the opposite attribute is not considered in the calculation, the result would be Indifferent. Using the formula, including the reverse attributes, the SI takes a negative value ( $S I-R=-0.38$ ), which would not be among the four quadrants proposed in Figure 3 and indicates that their satisfaction would decrease to levels that are substantially lower than desired. Considering that indifferent attributes are neutral for the client and the inclusion of reverses is not desirable, classifying an attribute as reverse rather than assuming it is indifferent is preferable. Likewise, $\mathrm{R} 2$ is a reverse requirement based on the majority of the answers. If we wanted to corroborate the information using the CS, the rating would be erroneously changed to indifferent.

Table 2. Examples of Classification of Reverses Attributes

\begin{tabular}{|c|c|c|c|c|c|c|c|c|c|c|c|c|c|c|c|}
\hline Req & $\mathrm{M}$ & 0 & A & I & $\mathrm{R}$ & Q & $\mathrm{T}$ & $\%$ 1st response & KANO & SI & DI & CS & SI-R & DI-R & CS-R \\
\hline R1 & 2 & 2 & 1 & 20 & 20 & 2 & 47 & $43 \%$ & R-I & 0,12 & 0,16 & 1 & $-0,38$ & 0,53 & $\mathrm{R}$ \\
\hline $\mathbf{R 2}$ & 3 & 0 & 5 & 12 & 27 & 0 & 47 & $57 \%$ & $\mathrm{R}$ & 0,25 & 0,15 & I & $-0,47$ & 0,64 & $\mathrm{R}$ \\
\hline
\end{tabular}

Step 3: Attribute Valuation. Based on Kano's model and the behavior of each of the attributes, two rates are established, a rate of absence and a rate of presence of each attribute, as shown in Figure 5. In this way, if the attractive (A) are present, they have a value of 1 or higher; if they are not present, their value is 0 . If must-be (M) is present, 
do not add customer satisfaction (0). If they are absent, they generate high dissatisfaction; thus, the rating is -1 or lower. The Indifferent (I) is the same regardless if they are present or not; in both cases, their value is 0 . The reverses $(\mathrm{R})$ are positively valued if they are absent (1); if they are present, dissatisfaction (-1) exists.

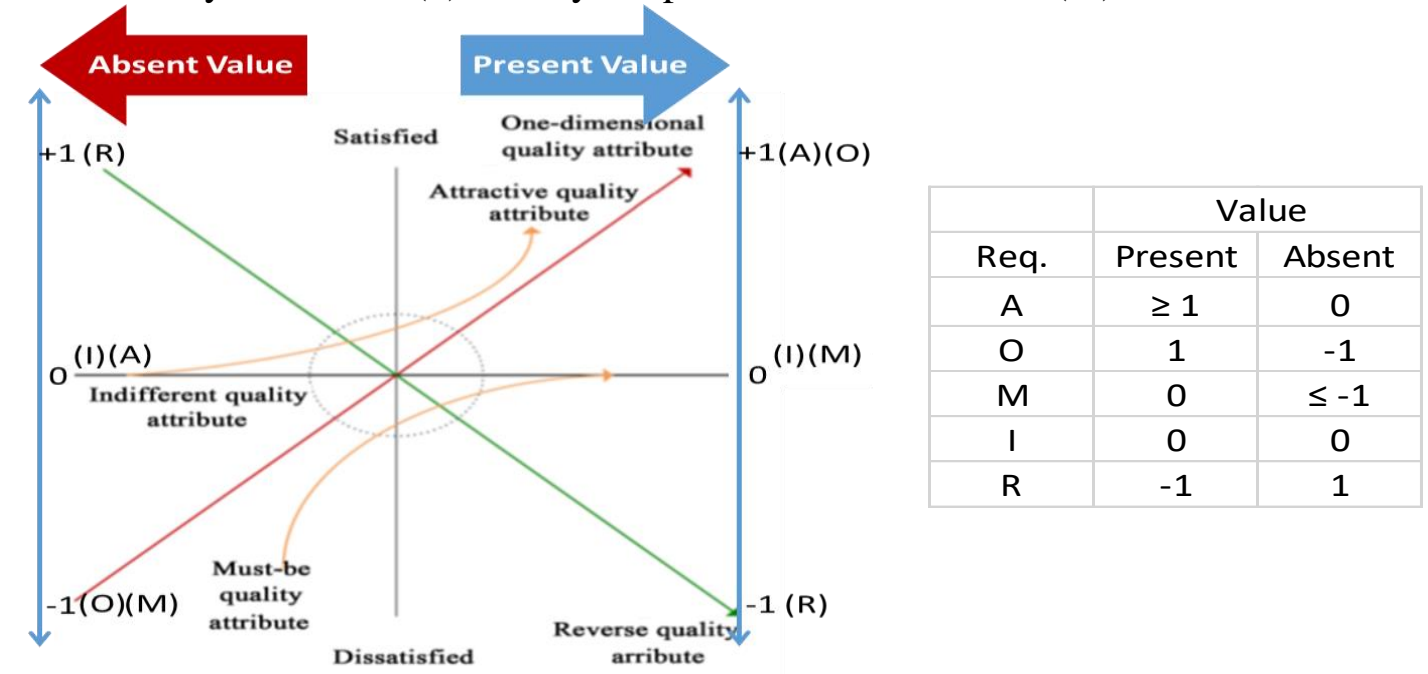

Figure 5 Attribute Valuation(Huang 2017)Edited version

After these rates have been defined, only the requirements that are expected are considered. One-dimensional and must-be attributes are expected to be present and reverses are expected to be absent. Attractive attributes are not expected, and with respect to the indifferent, the position is neutral, as shown in Table 3.

Table 3. Present and absent values of expected attributes

\begin{tabular}{cccc}
\hline & & \multicolumn{2}{c}{ Desired Value } \\
\hline Req. & Expected? & Presence & Absence \\
\hline Attractive (A) & No & - & - \\
\hline One-dimensional (O) & Yes, present & 1 & - \\
\hline Must-be (M) & Yes, present & 0 & - \\
\hline Indifferent (I) & Neutral & - & - \\
\hline Reverse (R) & Yes, absent & - & 1 \\
\hline
\end{tabular}

The classified attributes are multiplied by their values. All ratings are added, and the Desired Value Index is established, which is the sum of the ratings of all attributes with respect to the total number of attributes. The Potential Value Index is the sum of the desired value index and the percentage of attractive attributes.

\section{DETERMinATION OF THE VALUE GENERATED}

Value is generated in the design phase for the process and the product. Based on the list of attributes that were previously classified, designers will decide whether to incorporate the attributes that they consider within the design product and/or process. Berger et al.(1993) recommend prioritizing decisions in the following order: $\mathrm{M}>\mathrm{O}>$ $\mathrm{A}>\mathrm{I}$. Our recommendation is $\mathrm{M}>\mathrm{O}>\mathrm{R}$ (absence) $>\mathrm{A}>\mathrm{I}$. 
Finally, the number of attributes per type incorporated or not incorporated are added; these attributes are estimated to determine the value that was actually generated in the design. All ratings are added, and the Generated Value Index is established, which is the sum of the ratings of all present and absent attributes with respect to the total number of attributes. This index can be compared with the Desired Value Index and the Potential Value Index.

\section{EXAMPLE USING A CASE STUDY}

A case studied by (Huang 2017) is analyzed, which he applies Kano's model for the requirements analysis of a project consulting company based in Guangzhou; the main activity of the company is the design and construction of highways. Eighteen attributes were established (their names are not relevant), and 41 professionals were consulted among company managers and staff. For exercise purposes, two attributes that are considered reverses will be included for a total of 20 attributes.

\section{DETERMination OF DESIRED AND Potential VALUe INDEX}

Table 4 shows the classification of the attributes, according to Kano, the Coefficient of Satisfaction (CS) and the CS considering the Reverses (CS-R). The classification according to CS-R is the classification that will be conclusive. Therefore, we have 1 attractive attribute (A), 4 One-dimensional (O), 10 Must-be(M), 3 Indifferent (I) and 2 Reverse(R). To calculate the Desired Value Index, only O, M and R are considered; thus, we would have a desired value index of 0.30 . The potential value would be the latter added to the percentage of attractive attributes. The results are shown in Table 5.

Table 4. Attribute Classification(Huang 2017) Edited version

\begin{tabular}{|c|c|c|c|c|c|c|c|c|c|c|c|c|c|c|c|}
\hline \multirow{2}{*}{ Req } & Must be & One-d & Attract. & Indiffer. & Reverse & Quest & Total & $\%$ 1st & \multirow[b]{2}{*}{ KANO } & \multirow[b]{2}{*}{$\mathrm{SI}$} & \multirow[b]{2}{*}{ DI } & \multirow[b]{2}{*}{ CS } & \multirow[b]{2}{*}{$\mathrm{SI}-\mathrm{R} * *$} & \multirow[b]{2}{*}{$\mathrm{DI}-\mathrm{R} * *$} & \multirow[b]{2}{*}{ CS-R $* *$} \\
\hline & $\mathrm{M}$ & 0 & A & I & $\mathrm{R}$ & $\mathrm{Q}$ & $\mathrm{T}$ & response & & & & & & & \\
\hline R1 & 23 & 12 & 4 & 2 & 0 & 0 & 41 & $56 \%$ & $M$ & 0,39 & 0,85 & $M$ & 0,39 & 0,85 & M \\
\hline R2 & 24 & 11 & 4 & 1 & 0 & 1 & 41 & $59 \%$ & M & 0,38 & 0,88 & M & 0,38 & 0,88 & M \\
\hline R3 & 31 & 6 & 3 & 1 & 0 & 0 & 41 & $76 \%$ & M & 0,22 & 0,90 & M & 0,22 & 0,90 & M \\
\hline R4 & 27 & 3 & 5 & 4 & 1 & 1 & 41 & $66 \%$ & M & 0,21 & 0,77 & M & 0,18 & 0,78 & M \\
\hline R5 & 29 & 4 & 7 & 1 & 0 & 0 & 41 & $71 \%$ & M & 0,27 & 0,80 & $M$ & 0,27 & 0,80 & M \\
\hline R6 & 15 & 4 & 1 & 20 & 1 & 0 & 41 & $49 \%$ & 1 & 0,13 & 0,48 & 1 & 0,10 & 0,49 & 1 \\
\hline R7 & 13 & 9 & 14 & 3 & 0 & 2 & 41 & $34 \%$ & A & 0,59 & 0,56 & 0 & 0,59 & 0,56 & 0 \\
\hline R8 & 30 & 10 & 1 & 0 & 0 & 0 & 41 & $73 \%$ & M & 0,27 & 0,98 & $M$ & 0,27 & 0,98 & M \\
\hline R9 & 10 & 29 & 2 & 0 & 0 & 0 & 41 & $71 \%$ & 0 & 0,76 & 0,95 & 0 & 0,76 & 0,95 & 0 \\
\hline R10 & 32 & 8 & 1 & 0 & 0 & 0 & 41 & $78 \%$ & $\mathrm{M}$ & 0,22 & 0,98 & $\mathrm{M}$ & 0,22 & 0,98 & $\mathrm{M}$ \\
\hline R11 & 3 & 8 & 6 & 21 & 2 & 1 & 41 & $51 \%$ & 1 & 0,37 & 0,29 & 1 & 0,30 & 0,33 & 1 \\
\hline R12 & 25 & 8 & 2 & 4 & 1 & 1 & 41 & $61 \%$ & M & 0,26 & 0,85 & M & 0,23 & 0,85 & M \\
\hline R13 & 26 & 9 & 3 & 3 & 0 & 0 & 41 & $63 \%$ & M & 0,29 & 0,85 & M & 0,29 & 0,85 & M \\
\hline R14 & 20 & 13 & 4 & 3 & 0 & 1 & 41 & $49 \%$ & M & 0,43 & 0,83 & M & 0,43 & 0,83 & M \\
\hline R15 & 19 & 17 & 4 & 1 & 0 & 0 & 41 & $46 \%$ & $M$ & 0,51 & 0,88 & 0 & 0,51 & 0,88 & $\mathrm{O}$ \\
\hline R16 & 17 & 20 & 2 & 2 & 0 & 0 & 41 & $49 \%$ & $\mathrm{O}$ & 0,54 & 0,90 & $\mathrm{O}$ & 0,54 & 0,90 & 0 \\
\hline R17 & 7 & 9 & 19 & 5 & 1 & 0 & 41 & $46 \%$ & $A$ & 0,70 & 0,40 & A & 0,66 & 0,41 & A \\
\hline R18 & 5 & 13 & 3 & 16 & 3 & 1 & 41 & $39 \%$ & 1 & 0,43 & 0,49 & 1 & 0,33 & 0,53 & 1 \\
\hline R19* & 2 & 2 & 1 & 20 & 20 & 2 & 47 & $43 \%$ & R-I & 0,12 & 0,16 & I & $-0,38$ & 0,53 & $\mathrm{R}$ \\
\hline $\mathrm{R} 20^{*}$ & 3 & 0 & 5 & 12 & 25 & 0 & 45 & $56 \%$ & $\mathrm{R}$ & 0,25 & 0,15 & 1 & $-0,44$ & 0,62 & $\mathrm{R}$ \\
\hline \multicolumn{9}{|c|}{ *requirements included as an example } & \multicolumn{7}{|c|}{${ }^{* *}$ coefficient includes reverse requirements } \\
\hline
\end{tabular}

Table 5. Determination of Desired Value Index and Potential Value 


\begin{tabular}{|c|c|c|c|c|c|c|c|}
\hline \multirow[b]{2}{*}{ Req } & \multirow[b]{2}{*}{ Quantity } & \multirow[b]{2}{*}{$\%$} & \multicolumn{2}{|c|}{ Value } & \multicolumn{2}{|c|}{ Desired } & \multirow{2}{*}{ total } \\
\hline & & & present & absent & present & absent & \\
\hline$A$ & 1 & $5 \%$ & 1 & 0 & - & - & 0 \\
\hline 0 & 4 & $20 \%$ & 1 & -1 & 1 & - & 4 \\
\hline$M$ & 10 & $50 \%$ & $\mathrm{o}$ & -1 & o & - & $\mathrm{o}$ \\
\hline 1 & 3 & $15 \%$ & o & $\mathrm{o}$ & - & - & o \\
\hline \multirow[t]{5}{*}{$\mathrm{R}$} & 2 & $10 \%$ & -1 & 1 & - & 1 & 2 \\
\hline & 20 & $100 \%$ & & & & & 6 \\
\hline & & & & & DVI & $6 / 20$ & 0,30 \\
\hline & & & & & PVI & & 0,35 \\
\hline & & & & & DVI/PVI & & 0,86 \\
\hline
\end{tabular}

\section{DETERMINATION OF GENERATED VALUE INDEX}

Following the previous example, different hypothetical scenarios are shown. Value 1 has been considered for the presence of an attractive attribute, and -1 has been considered for the absence of a must-be attribute. These values can be modified according to the importance of the impact of the presence/absence of these attributes and can be higher than 1 or lower than -1. Table 6 shows the 3 possible scenarios.

Table 6. Determination of Generated Value Index. Three possible scenarios.

\begin{tabular}{|c|c|c|c|c|c|c|c|c|c|c|c|c|}
\hline & \multirow[b]{2}{*}{ Quantity } & \multicolumn{2}{|c|}{ Value } & \multicolumn{3}{|c|}{$\begin{array}{l}\text { Scenario } 1 \\
\text { Attributes }\end{array}$} & \multicolumn{3}{|c|}{$\begin{array}{l}\text { Scenario } 2 \\
\text { Attributes }\end{array}$} & \multicolumn{3}{|c|}{$\begin{array}{l}\text { Scenario } 3 \\
\text { Attributes }\end{array}$} \\
\hline & & present & absent & present & absent & score & present & absent & score & present & absent & score \\
\hline A & 1 & 1 & 0 & 1 & 0 & 1 & 0 & 1 & 0 & 1 & 0 & 1 \\
\hline 0 & 4 & 1 & -1 & 3 & 1 & 2 & 4 & 0 & 4 & 4 & 0 & 4 \\
\hline M & 10 & 0 & -1 & 9 & 1 & -1 & 10 & 0 & 0 & 10 & 0 & 0 \\
\hline 1 & 3 & 0 & 0 & 3 & 0 & 0 & 1 & 2 & 0 & 1 & 2 & 0 \\
\hline \multirow[t]{3}{*}{$\mathrm{R}$} & 2 & -1 & 1 & 1 & 1 & 0 & 0 & 2 & 2 & 0 & 2 & 2 \\
\hline & 20 & & & 17 & 3 & 2 & 15 & 5 & 6 & 16 & 4 & 7 \\
\hline & & & & & GVI & 0,10 & & GVI & 0,30 & & GVI & 0,35 \\
\hline \multicolumn{2}{|c|}{ DVI 0,30} & \multicolumn{3}{|c|}{ Desired value fulfillment } & DVF & $33 \%$ & & DVF & $100 \%$ & & DVF & $117 \%$ \\
\hline \multicolumn{2}{|c|}{ PVI 0,35} & \multicolumn{3}{|c|}{ Potential value fulfillment } & PVF & $29 \%$ & & PVF & $86 \%$ & & PVF & $100 \%$ \\
\hline
\end{tabular}

Scenario 1. Loss of value. Not all expected attributes were satisfied. The desired value was an index of 0.30 (DVI), and 0.10 was obtained (GVI), i.e., 33\% of the value expectation was satisfied. With respect to the potentially possible value (PVI), only $29 \%$ of the value expectation was achieved (PVF).

Scenario 2. Fulfillment of $\mathbf{1 0 0 \%}$ of the desired value. In this case, all expected attributes were satisfied, i.e., all must-be, and one-dimensional attributes were included, and opposites were excluded. 100\% of the desired value was achieved (DVI=GVI). With respect to the potentially possible value (PVI), 86\% was satisfied (PVF).

Scenario 3. Fulfillment of potential value. In this case, all expected attributes were satisfied, and due to the incorporation of attractive attributes $100 \%$ of the potentially possible value was achieved.

\section{CONCLUSIONS}

The model is flexible and adaptable to various study needs. With respect to the attributes to be evaluated, the model can be channeled to a specific area; for example, it is possible to apply this model if you want to evaluate the value generated by sustainability aspects or in another area. In the same way, the value expectations of one target population or how the different design schemes satisfy the conditions of customer satisfaction can be compared. 
The application of the developed value analysis model favors the identification of the desired value of the different clients within the design process, the understanding of value generation, and the timely identification of value losses. The use of value indexes supports the design process in improving the capture of requirements and the knowledge of customer satisfaction conditions. The inclusion of 3 indexes that can be used separately or simultaneously is a key factor of this model. The comparison of the value generated with respect to the desired or potential value indexes can be applied to determine the value losses related to noncompliance with the desired value or the potentially possible value. With these Value indexes is possible clearly identify when the desired value is not satisfied, when the desired value is satisfied but the potentially possible value is not satisfied, and when this potential value is satisfied, which may exceed the desired value depending on the attractive value considerations that exist in the study. Evolution of the different indexes can also be investigated, which demonstrates the dynamic change in customer preferences.

The benefits of the model have not been quantified, but it is expected that designers can make informed decisions in the process, avoiding value losses and generating the value required by different customers. Among the challenges associated with the model is the incorporation of the resources that are employed as part of the value equation and the evaluation of the impact that the incorporation of the proposed value indexes may have in the process.

\section{ACKNOWLEDGMENTS}

The authors would like to acknowledge the funding and support provided by FONDECYT (1181648) and GEPUC to develop this research and CONICYTPCHA/National Doctorate/2016-21160571 for funding the postgraduate studies of Zulay Giménez.

\section{REFERENCES}

Andi, \& Minato, T. (2003). Design documents quality in the Japanese construction industry: Factors influencing and impacts on construction process. International Journal of Project Management. https://doi.org/10.1016/S0263-7863(02)00083-2

Arge, K. (2008). Tverrfaglighet og fagkompetanse i prosjekters tidligfase. Oslo, Norway, Norway.

Arroyave, C., Maya, A., \& Orozco, C. (2007). Aplicación de la metodología qfd en el proceso de ingeniería de requisitos. Universidad EAFIT, Medellín, Colombia.

Association Francaise de Normalisation. (2000). French standard NF EN 12973. France.

Berger, C., Blauth, R., Boger, D., Buss, D., Dambolena, I., Graham, A., ... Wood, R. (1993). Kano's Methods for Understanding Customer-defined Quality. Cambridge, MA. USA.

Bølviken, T., Rooke, J., \& Koskela, L. (2014). The Wastes of Production in Construction - A TFV Based Taxonomy. In 22nd Annual Conference of the International Group for Lean Construction (p. pp 811-822). Oslo, Norway.

Cuperus, Y., \& Napolitano, P. (2005). Open building/Lean Construction evaluation of 
a case in Brazil. In 13th Annual Conference of the International Group for Lean Construction. (pp. 457-462). Sydney, Australia.

Drevland, F., \& Lohne, J. (2015). Nine tenets on the nature of value. In 23rd Annual Conference of the International Group for Lean Construction (pp. 475-485). Perth, Australia.

Hevner, A. R. (2007). A Three Cycle View of Design Science Research A Three Cycle View of Design Science Research. Scandinavian Journal of Information Systems, 19(2), 87-92. https://doi.org/http://aisel.aisnet.org/sjis/vol19/iss2/4

Huang, J. (2017). Application of Kano Model in Requirements Analysis of Y Company's Consulting Project. American Journal of Industrial and Business Management, 7, 910-918. https://doi.org/10.4236/ajibm.2017.77064

Knotten, V., Svalestuen, F., Laedre, O., \& Hansen, G. (2016). Improving Design Management With Mutual Assessment'. In 24th Conference of the International Group for Lean Construction (pp. 173-182). Boston, U.S.A.

Koskela, L. (2000). An exploration towards a production theory and its application to construction.PhD Dissertation. Helsinki University of Technology, Finland. Retrieved from http://www.inf.vtt.fi/pdf/

Kumar, V., \& Whitney, P. (2007). Daily Life, not markets: customer-centered design. Journal of Business Strategy, 28(4), 46-58. https://doi.org/https://doi.org/10.1108/02756660710760944

Lee, B. D., \& Paredis, C. J. J. (2014). A conceptual framework for value-driven design and systems engineering. In Procedia CIRP. https://doi.org/10.1016/j.procir.2014.06.147

Leung, M.-Y., \& Liu, A. M. M. (1998). Developing a value management model by value-goal system approach. In 14th Annual ARCOM Conference (Vol. 2, pp. 496-505). University of Reading. Association of Researchers in Construction Management, Vol. 2, 496-505. .

Love, P. E. D., Lopez, R., \& Edwards, D. J. (2013). Reviewing the past to learn in the future : making sense of design errors and failures in construction. Structure and Infrastructure Engineering, 2479(June), 675-688. https://doi.org/10.1080/15732479.2011.605369

Macomber, H., Howell, G., \& Barberio, J. (2007). Target-Value Design: Nine Foundational Practices for Delivering Surprising Client Value. AIA Practice Management Digest.

Male, S., Bower, D., \& Aritua, B. (2007). Design management: changing roles of the professions. Proceedings of the Institution of Civil Engineers - Management, $\begin{array}{llll}\text { Procurement Law, } & \text { 160(2), }\end{array}$ https://doi.org/10.1680/mpal.2007.160.2.75

Matzler, K., Hinterhuber, H., Franz, B., \& Sauerwein, E. (1996). How to delight your customers. Journal of Product \& Brand Management, 5(2), 6-18. https://doi.org/https://doi.org/10.1108/10610429610119469

Orihuela, P., Orihuela, J., \& Pacheco, S. (2015). Communication Protocol for Implementation of Target Value Design (TVD) in Building Projects. In Procedia Engineering. https://doi.org/10.1016/j.proeng.2015.10.048 
Rachwan, R., Abotaleb, I., \& Elgazouli, M. (2016). The Influence of Value Engineering and Sustainability Considerations on the Project Value. Procedia Environmental Sciences, 34, 431-438. https://doi.org/10.1016/j.proenv.2016.04.038

Rybkowski, Z. K., Shepley, M., \& Ballard, G. (2012). Target value design: Applications to newborn intensive care units. Health Environments Research and Design Journal, 5(4), 5-23.

Saxon, R. (2005). Be Valuable. Report of Value Task Group. Constructing Excellence. London, UK. Retrieved from www.constructingexcellence.org.uk

Spiten, T. K., Haddadi, A., Støre-Valen, M., \& Lohne, J. (2016). Enhancing Value for end users. A Case study of end-user involvement. In 24th Annual Conference of the International Group for Lean Construction (pp. 153-162). Boston, MA, USA.

The Standish Group. (2014). Chaos Report. Project Smart. Retrieved from https://www.projectsmart.co.uk/white-papers/chaos-report.pdf

Tontini, G. (2002). Deployment of customer needs in the QFD using a modified Kano model Maturity of Organizations Management-dynamic models of maturity in innovation management and its relationship with organizational performance View project. Retrieved from www.researchgate.net/publication/291783561

Womack, J., \& Jones, D. (1996). Lean Thinking. Banish waste and create wealth in your corporation. (S. and S. London, Ed.). 
Giménez, Z., Mourgues, C., Alarcón, L.F., Mesa, H 